\title{
Graphene and Other Carbon Sorbents for Selective Adsorption of Thiophene from Liquid Fuel
}

\author{
Lifeng Wang and Ralph T. Yang \\ Dept. of Chemical Engineering, University of Michigan, Ann Arbor, MI 48109
}

Chia-Liang Sun

Dept. of Chemical and Materials Engineering, Chang Gung University, Kwei-Shan, Tao-Yuan 333, Taiwan

DOI 10.1002/aic.13896

Published online August 10, 2012 in Wiley Online Library (wileyonlinelibrary.com).

\begin{abstract}
Significance
Four types of carbons (activated carbon, Maxsorb superactivated carbon, mesoporous templated carbon CMK-3, and graphene) were investigated as selective sorbents for adsorption of thiophene from its solution in n-octane. Graphene showed clearly the highest sulfur capacity. The relative sulfur capacities correlated well with the relative heats of adsorption. The carbene-type zigzag edge sites and the carbyne-type armchair edge sites on graphene are among the possible sites for strong interactions with thiophene.
\end{abstract}

Keywords: adsorption/liquid, materials, fuels

$\mathrm{D}$ esulfurization of liquid hydrocarbon fuels and coalderived liquids has attracted intense research interests. ${ }^{1,2}$ Deep desulfurization of transportation fuels has been mandated by the United States and is also needed for fuel cell applications. ${ }^{2}$ Various types of adsorbents such as mixed metal oxides, zeolites, activated carbon, clays and mesoporous materials have been developed and investigated. ${ }^{2-11}$ Among carbon materials, nanostructured carbons, ordered mesoporous carbon (CMK-n), and graphene, have recently attracted much research interest. Mesoporous carbons, having the features of controllable porosity, ordered and uniform pore sizes and high-surface areas, have been studied and applied in the fields of battery electrodes, supercapacitors, adsorbents, and catalysis. ${ }^{12,13}$ Graphene, a oneatom-thick planar sheet of $s p^{2}$-bonded carbon atoms that are densely packed in a honeycomb crystal lattice, has shown fascinating characteristics of the quantum Hall effect, extremely high-carrier mobility, ambipolar field-effect, sensitive response to single molecules, and is currently a research topic of intense interest. ${ }^{14,15}$ However, the desulfurization

\footnotetext{
Additional Supporting Information can be found in the online version of this article.

Correspondence concerning this article should be addressed to R. T. Yang at yang@umich.edu.

(C) 2012 American Institute of Chemical Engineers
}

properties of these carbons have not been studied. In this Letter, four types of carbon sorbents, mesoporous carbon, graphene, activated carbon and superactivated carbon Maxsorb were investigated for the adsorption of thiophene from the liquid mixture of thiophene/n-octane. These typical carbon sorbents were studied and compared as potential candidates for desulfurization of transportation fuels.

The synthesis and characterization details of these carbon sorbents were described in Supplementary Materials. The surface areas and porosities of the four carbon sorbents were evaluated by nitrogen adsorption at $77 \mathrm{~K}$ and shown in Figure 1. The isotherm of activated carbon (AC) exhibited a Type I curve, thus, showing the presence of microporosity. The BET surface area and pore volume were $1040 \mathrm{~m}^{2} / \mathrm{g}$ and $0.57 \mathrm{~cm}^{3} / \mathrm{g}$, respectively. These textural properties are comparable to those of typical activated carbons. ${ }^{16}$ The isotherm of the Maxsorb carbon exhibited a steep increase at low pressure and a slow increase before 200 Torr, indicating the presence of micropores and some larger pores. The BET surface area and pore volume of the Maxsorb carbon were 3311 $\mathrm{m}^{2} / \mathrm{g}$ and $1.7 \mathrm{~cm}^{3} / \mathrm{g}$, which were among the highest for activated carbons. ${ }^{16}$ The high-surface area and porosity of Maxsorb resulted from the molten alkali $(\mathrm{KOH})$ activation process, which is an established method for producing highly microporous carbon. For mesoporous carbon (CMK-3), the nitrogen isotherm clearly exhibited the Type IV behavior 


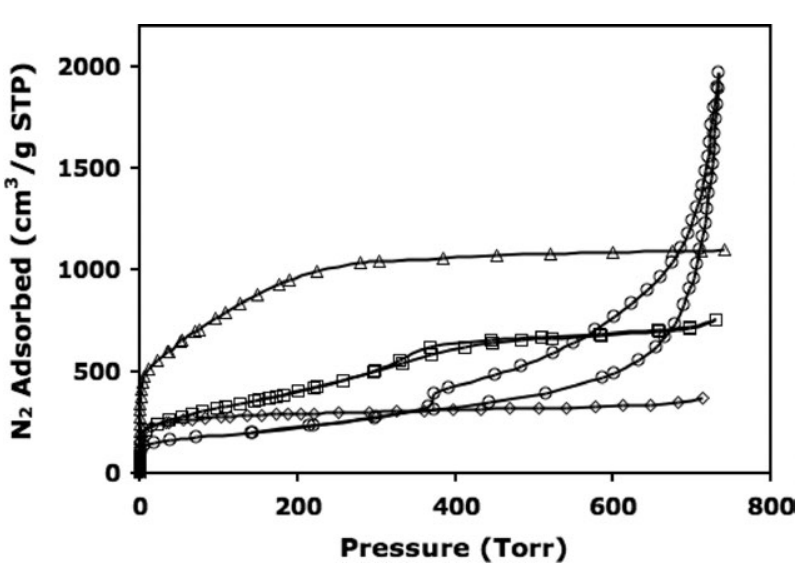

Figure 1. Nitrogen isotherms at $77 \mathrm{~K}$ for Maxsorb $(\triangle)$, mesoporous carbon CMK-3 $(\square)$, AC $(\diamond)$ and graphene (○).

with a hysteresis loop, indicating the presence of mesoporosity. ${ }^{12,13}$ The BET surface area and pore volume were 1273 $\mathrm{m}^{2} / \mathrm{g}$ and $1.2 \mathrm{~cm}^{3} / \mathrm{g}$ for CMK-3. For graphene, the isotherm exhibited a Type-I curve at low-relative pressures and a Type-IV curve with a hysteresis loop at higher pressures. This indicated the presence of microporosity, mesoporosity, and some macroporosity. The huge hysteresis loop in the higher relative pressure (larger than 0.4 ) indicated the presence of a large amount of mesopores and macropores. It is noted that the BET surface area of graphene was $708 \mathrm{~m}^{2} / \mathrm{g}$, which was lower than the theoretical surface area of 2630 $\mathrm{m}^{2} / \mathrm{g}$ for a single isolated graphene sheet. This was due to the overlap and stacking of the exfoliated graphene layers,

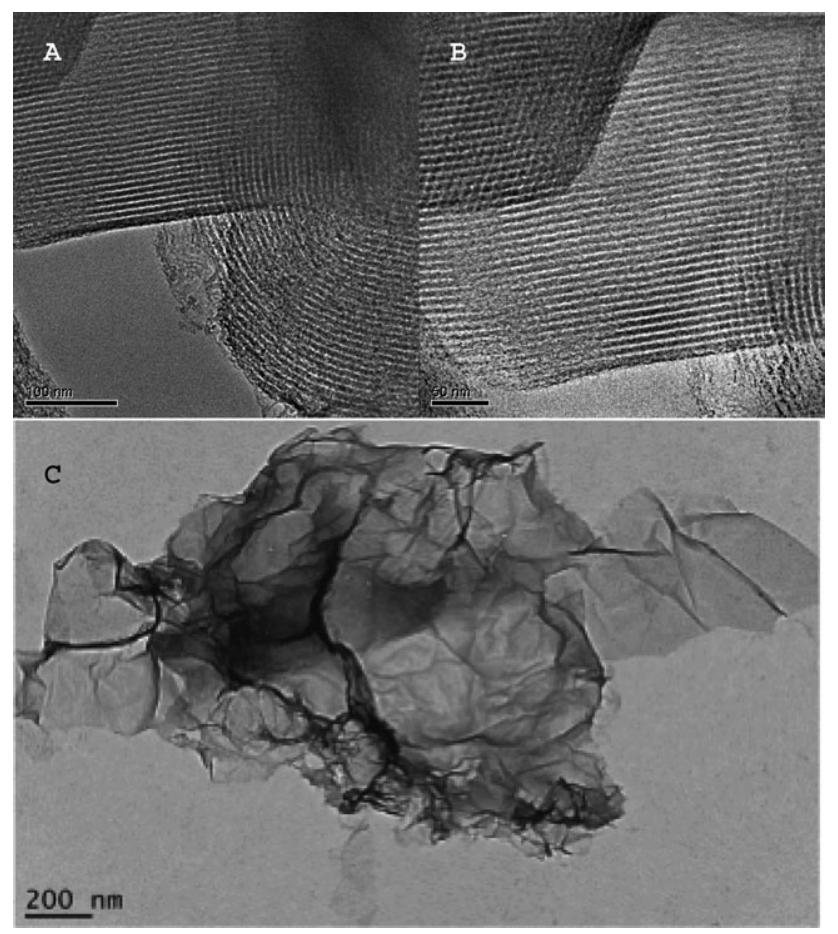

Figure 2. TEM images of (A, B) mesoporous templated carbon $\mathrm{CMK}-3$, and $(C)$ graphene.

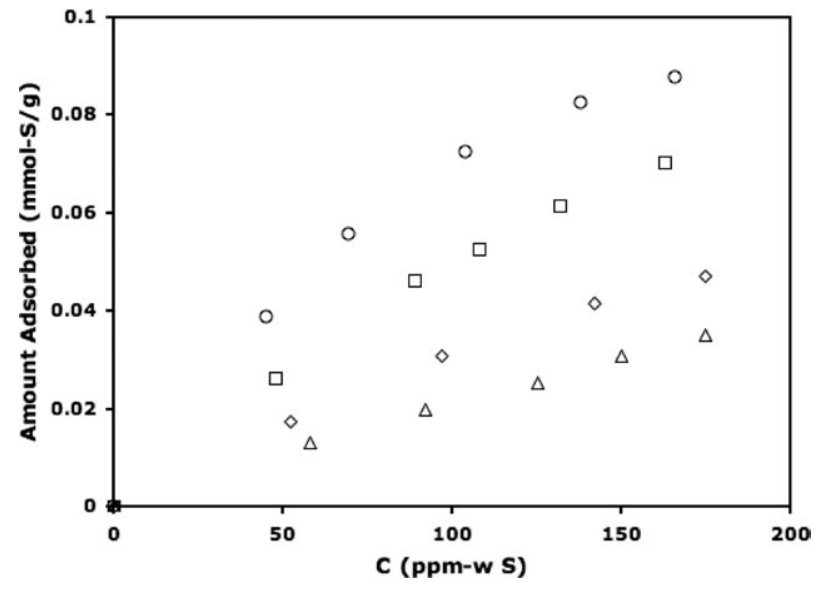

Figure 3. Adsorption isotherms of thiophene in $n$-octane at $293 \mathrm{~K}$ on $\mathrm{AC}(\triangle)$, Maxsorb superactivated carbon $(\diamond)$, mesoporous carbon CMK-3 $(\square)$, and graphene (○).

which was also responsible for the formed mesopores and macropores.

To characterize the structure of the synthesized CMK-3 and graphene, transmission electron microscopy was performed on these samples. The images of CMK-3 showed well-ordered mesostructure (Figures 2A and 2B). The TEM image of graphene showed a wrinkled and agglomerated graphene sheet-like structure (Figure 2C). The graphene layers were overlapped and connected to form mesoporosity and macroporosity, which were consistent with the nitrogen adsorption results.

The adsorption isotherms were measured in the low concentration range of thiophene sulfur (0-200 ppmw-S) for simulating the thiophene contained in commercial fuels. The equilibrium isotherms for the adsorption of thiophene from binary solutions in $n$-octane on AC, Maxsorb, CMK-3 and graphene are shown in Figure 3. Clearly, all carbon sorbents could adsorb thiophene from octane, and the adsorbed amount of thiophene continued to increase with the increase in concentration for all carbon sorbents. It is interesting to note that the thiophene adsorption capacities of these carbon sorbents followed the order of graphene $>$ CMK-3 $>$ Maxsorb $>\mathrm{AC}$, which was different from the order of the BET surface areas of these carbon sorbents. Maxsorb, with the highest BET surface area among all the carbons tested, showed a low capacity, while graphene with the lowest surface area adsorbed the largest amount of thiophene uptake. These results indicated that surface area is not a critical factor influencing sulfur adsorption capacity of carbon sorbents. Normalized by the BET surface areas, the difference in the thiophene adsorption capacities among these sorbents became clearer. The normalized thiophene capacities per 500 $\mathrm{m}^{2} / \mathrm{g}$ sorbent were $0.06 \mathrm{mmol}-\mathrm{S}$ for graphene, $0.027 \mathrm{mmol}-\mathrm{S}$ for CMK-3, $0.017 \mathrm{mmol}-\mathrm{S}$ for AC, and $0.007 \mathrm{mmol}-\mathrm{S}$ for Maxsorb. Clearly, graphene had a superior capacity for thiophene compared to other carbon sorbents. To the best of our knowledge, this is the first study of the desulfurization property of graphene. To understand the difference in the desulfurization capacity among these sorbents, we further 

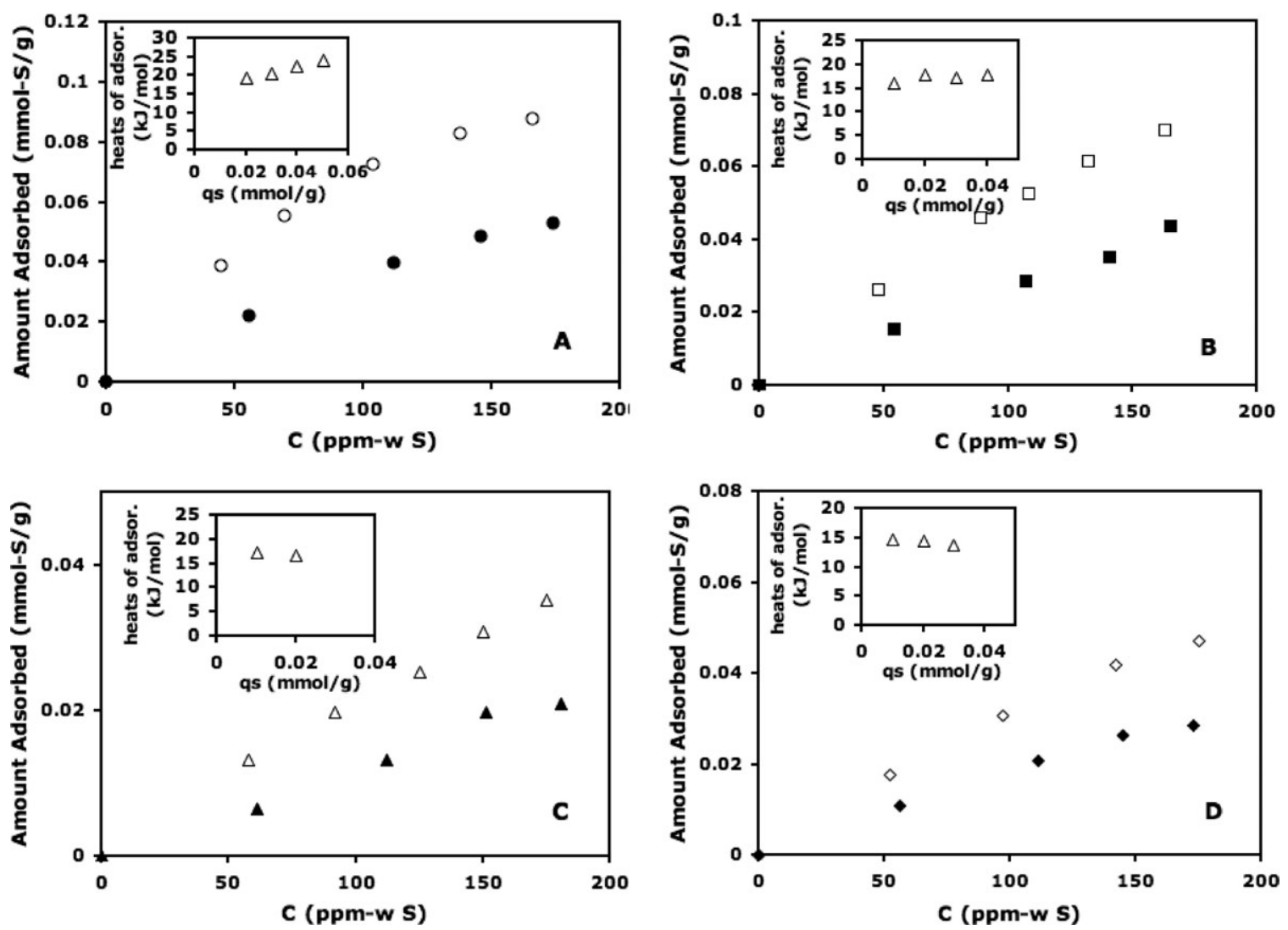

Figure 4. Temperature dependence of thiophene adsorption isotherms on (A) graphene, (B) mesoporous carbon CMK-3, (C) AC and (D) Maxsorb at $293 \mathrm{~K}$ (empty symbol), and $323 \mathrm{~K}$ (solid symbol), and isosteric heats of adsorption (insets).

investigated and compared the temperature dependence of thiophene adsorption isotherms and heats of adsorption on these sorbents.

The heats of adsorption are known to be critical in estimating the performance of an adsorptive separation process and understanding the adsorption process. Figure 4 shows the equilibrium isotherms of thiophene from the binary $n$-octane solution on Maxsorb, AC, CMK-3 and graphene at 293 and $323 \mathrm{~K}$. Since adsorption is an exothermic process, the adsorption amount of thiophene decreased on all carbon sorbents as temperature was increased from 293 to $323 \mathrm{~K}$. Isosteric heats of adsorption were calculated using the Clausius-Clapeyron equation (see Supplementary Material). As shown in Figure 4 insets, the isosteric heats $q_{s t}$ were $\sim 19-24$ $\mathrm{kJ} / \mathrm{mol}$ for graphene, $\sim 16-18 \mathrm{~kJ} / \mathrm{mol}$ for CMK-3, $\sim 17 \mathrm{~kJ} /$ mol for AC, and $\sim 14-15 \mathrm{~kJ} / \mathrm{mol}$ for Maxsorb. This result can be attributed to a number of possible reasons. The heats of adsorption on these sorbents were in fair agreement with their specific adsorption capacities. The higher heat of adsorption on graphene indicated the presence of more energetic sites on graphene. It is known that defect sites and edge sites (i.e., armchair and zigzag edge sites), and their joint corner sites could act as active sites for adsorption. ${ }^{17,18}$ As discussed by Radovic and Bockrath, ${ }^{17}$ the carbene-type zigzag edge sites (i.e., with two unshared valence electrons), as well as the carbyne (with a triple bond between two $\mathrm{C}$ atoms) type armchair edges are highly active and they dic- tate the electronic and surface properties. The strong interactions between thiophene and graphene could possibly be attributed to the electrostatic interactions with these edge sites. The connectivity, variation in size and shape of the graphene sheets, and number of stacked graphene sheets that formed the pore walls caused the energetic heterogeneity. The sulfuric acid and nitric acid treatments during sample preparation also contributed to forming heterogeneous sites on graphene. It was reported that acid functional groups on carbon surface strengthened the adsorption of sulfur-containing compounds. ${ }^{19,20}$ Acid functional groups (e.g., carboxylic groups) are complementary to the lone pair of electrons of the sulfur atoms of thiophene. ${ }^{19,20}$ For Maxsorb, the $\mathrm{KOH}$ process during synthesis of Maxsorb removed the acid groups, which explained its low-sulfur adsorption capacity. It is noteworthy that although all these carbon sorbents could adsorb thiophene from $n$-octane, their capacity for thiophene was not high when compared to bulky thiophenic sulfur or adsorption on modified sorbents. From the heats of adsorption results, it is known that this was due to the relatively weak interactions between the small thiophene molecule and the carbon sorbents.

In brief, four types of carbons (activated carbon, Maxsorb superactivated carbon, mesoporous carbon CMK-3, and graphene) were investigated for adsorption of thiophene from its binary solutions in $n$-octane. We found that graphene had a superior capacity toward thiophene compared to other 
carbon sorbents. The adsorption capacities for thiophene followed the order: graphene $>$ CMK-3 $>$ Maxsorb $>$ AC. Surface area is not a critical factor influencing sulfur capacity of carbon sorbents. The relative sulfur adsorption capacities were correlated well with the relative heats of adsorption. Further detailed study is needed to understand the desulfurization performance of these carbon sorbents.

\section{Acknowledgments}

The authors acknowledge funding from NSF CBET-0852129. We thank Jheng-Sin Su of Chang Gung University for his help in the preparation of graphene.

\section{Literature Cited}

1. Gates BC. Kinetics and Mechanism of Desulfurization and Denitrogenation of Coal-derived Liquids. Springfield, Washington, DC: US Dept of Energy; 1976.

2. Hernández-Maldonado AJ, Yang RT. Desulfurization of transportation fuels by adsorption. Catal Rev Sci Eng. 2004;46:111-150.

3. Padin J, Yang RT, Munson CL. New sorbents for olefin/ paraffin separations and olefin purification for C4 hydrocarbons. Ind Eng Chem Res. 1999;38:3614-3621.

4. Yang RT.Sorbents for Applications, in Adsorbents: Fundamentals and Applications. Hoboken, NJ: John Wiley and Sons, Inc; 2003.

5. Chica A, Strohmaier K, Iglesia E. Adsorption, desorption, and conversion of thiophene on H-ZSM5. Langmuir. 2004;20:10982-10991.

6. Wang SQ, Zhou L, Su W, Sun Y, Zhou YP. Deep desulfurization of transportation fuels by characteristic reaction resided in adsorbents AIChE J. 2009,55: 1872-1881.

7. Li W, Liu QF, Xing JM, Gao HS, Xiong XC, Li YG, Li $X$, Liu HZ. High-efficiency desulfurization by adsorption with mesoporous aluminosilicates. AIChE J. 2007, 53:3263-3268.

8. Jeon HJ, Ko CH, Kim SH, Kim JN. Removal of refractory sulfur compounds in diesel using activated carbon with controlled porosity. Energy Fuels. 2009;23:2537-2543.
9. King DL, Faz C. Desulfurization of tier 2 gasoline by divalent copper-exchanged zeolite Y. Appl Catal A. 2006;311:58-65.

10. Yang HY, Sothen R, Cahela DR, Tatarchuk BJ. Breakthrough Characteristics of reformate desulfurization using $\mathrm{ZnO}$ sorbents for logistic fuel cell power systems. Ind Eng Chem Res. 2008;47:10064-10070.

11. Landau MV, Herskowitz M, Agnihotri R, Kegerreis JE. Ultradeep adsorption-desulfurization of gasoline with $\mathrm{Ni}$ / Al-SiO2 material catalytically facilitated by ethanol. Ind Eng Chem Res. 2008;47:6904-6916.

12. Jun S, Joo S. H, Ryoo R, Kruk M, Jaroniec M, Liu Z, Ohsuna T, Terasaki O. Synthesis of new, nanoporous carbon with hexagonally ordered mesostructure. $J \mathrm{Am}$ Chem Soc. 2000;122:10712-10713.

13. Roo R, Joo SH, Kruk M, Jaroniec M. Ordered mesoporous carbons. Adv Mater. 2001;13:677-681.

14. Geim AK, Novoselov KS. The rise of graphene. Nat Mater. 2007;6:183-191.

15. Zhang Y, Guo L, Wei S, He Y, Xia H, Chen Q, Sun HB, Xiao FS. Direct imprinting of microcircuits on graphene oxides film by femtosecond laser reduction. Nano Today. 2010;5:15-20.

16. Wang L, Yang RT. Hydrogen storage on carbon-based adsorbents and storage at ambient temperature by hydrogen spillover. Catal Rev Sci Eng. 2010;52(4):411-461.

17. Radovic LR. Bockrath B. On the chemical nature of graphene edges: origin of stability and potential for magnetism in carbon materials. J Am Chem Soc. 2005; 127:5917-5927.

18. Radovic LR. Active sites in graphene and the mechanism of $\mathrm{CO} 2$ formation in carbon oxidation. $\mathrm{J}$ Am Chem Soc. 2009;131:17166-17175.

19. Jiang ZX, Liu Y, Sun XP, Tian FP, Sun FX, Liang CH, et al. Activatedcarbons chemically modified by concentrated $\mathrm{H} 2 \mathrm{SO} 4$ for the adsorption of the pollutants from wastewater and dibenzothiophene from fuel oils. Langmuir. 2003;19:731-736.

20. Yang YX, Liu HY, Ying PL, Jiang ZX, Li C. Selective dibenzothiophene adsorption on modified activated carbons. Carbon. 2007;45:3042-3044.

Manuscript received Jun. 14, 2012. 